\title{
Okul öncesi öğretmenlerinin kariyer uyumlulukları ve çocuklar için kullandıkları mutluluk artırıcı stratejiler arasındaki ilişkinin incelenmesi
}

\author{
Examining the relationship between preschool teachers' career \\ adaptability and happiness-enhancing strategies for children
}

Özkan Sapsağlam ${ }^{1}$, Rıdvan Karabulut ${ }^{2}$, İpek Ekici ${ }^{3}$

\begin{abstract}
Makale Geçmişi
Geliş : 13 Eylül 2020

Düzeltme : 9 Mart 2021

Kabul : 17 Nisan 2021
\end{abstract}

\section{Makale Türü}

Arastorma Makalesi
Article History

Received : 13 September 2020

Revised : 9 March 2021

Accepted : 17 April 2021

\section{Article Type}

Research Article
Öz: Bireyin akademik yaşamında ilk karşılaştığı formal eğitim kurumları okul öncesi eğitim kurumları ve hayatına giren ilk öğretmenler okul öncesi öğretmenleridir. Okul öncesi Öğretmenlerinin Kariyer Uyumlulukları ve Çocuklar İçin Kullandıkları Mutluluk Artırıcı Stratejiler arasındaki ilişkinin incelenmesi amacıyla yapılan araştırmada, nicel araştırma desenlerinden ilişkisel tarama modeli tercih edilmiştir. Örneklemin belirlenmesinde amaçlı örnekleme yöntemlerinden maksimum çeşitlilik örnekleme yöntemi kullanılmış ve araştırmanın örneklemini farklı okul öncesi eğitim kurumlarında çalışan 229 okul öncesi öğretmeni oluşturmuştur. Araştırma verilerinin normal dağılımı incelenmiş ve analiz sonucunda parametrik olmayan analiz yöntemlerinin kullanılmasına karar verilmiştir. Araştırma sonucunda okul öncesi öğretmenlerinin kariyer uyumluluklarının ve çocuklar için kullandıkları mutluluk artırıcı stratejilerin mesleğini sevme ve mesleğini seçme durumlarına göre anlamlı düzeyde farklılaştığı, kariyer uyumlulukları ve çocuklar için kullandıkları mutluluk artırıcı stratejiler arasında pozitif yönlü ve anlamlı ilişki olduğu ve kariyer uyumluluğu yüksek öğretmenlerin mutluluk artırıcı strateji kullanım düzeylerinin de yüksek olduğu görülmüştür.

Anahtar Kelimeler: Okul öncesi dönem, Okul öncesi öğretmeni, Kariyer uyumluluğu, Mutluluk artırıc strateji kullanımı.

Abstract: Formal education institutions that individuals first encounter in their academic life are early childhood education institutions and teachers that they first meet are preschool teachers. This study aimed to investigate the relationship between the career adaptability of preschool teachers and the happiness-increasing strategies that they use for children. To this end, the study used a correlational survey design. The study sampled 229 preschool teachers working in different early childhood education institutions using maximum variation sampling. The normality of the data was tested. As a result of the analysis, they were analysed using nonparametric tests. The analysis results showed that preschool teachers' levels of career adaptability and using happiness-increasing strategies for children differed significantly according to career choice and liking the job. A significant positive correlation was found between preschool teachers' levels of career adaptability and using happinessincreasing strategies for children. Accordingly, preschool teachers with high career adaptability also had a high level of using happiness-increasing strategies.

Keywords: Early childhood, preschool teachers, career adaptability, happiness-increasing strategies 


\section{SUMMARY}

\section{Introduction}

Early childhood education institutions are the first formal education institutions that enter a child's life. Positive experiences and practices that children have in early childhood education institutions enable them to have a positive motivation towards the next levels of formal education. The most important component of early childhood education institutions is obviously the teacher. Teachers have a substantial impact on students' academic achievement, attitudes, behaviours, experiences, and relationships at school.

Teachers are the most important components of education and affect children's personality development and many other characteristics Preschool teachers are the most important factor in the educational process and the nature of early childhood education Studies have found that teachers have an approximately 25\% effect on students' happiness and academic achievement.

Happiness (subjective well-being) is defined as the predominance of positive emotions over negative emotions and satisfaction with life. As of age two, children start to notice and understand emotions such as happiness, sadness, resentment, and fear. The increase in children's happiness allows them to look at life positively and interact positively with those around them. The feeling of happiness must be strong, especially in the early years of life, to able to have a positive outlook on life and cherish hope. Decreased happiness and life satisfaction may lead to problems such as decreased academic achievement, poor friendships, loneliness, depression, and substance abuse.

\section{Method}

The study used a correlational survey research design. Correlational survey is a quantitative research method used to find out whether there is a relationship between two or more variables or determine the degree of their relationship

Pre-school teacher composed the research population. The sample consisted of 229 preschool teachers working in preschool education institutions located in Kırşehir in the fall semester of the 2019-2020 academic year. The sample group was selected using maximum variation sampling. Accordingly, pre-school teachers working in early childhood education institutions of different socioeconomic levels (state kindergarten, private kindergarten, and nursery class) were included in the sample group.

The data were collected using a "Personal Information Form", the "Career Adaptability Scale", and the "Scale of Happiness Strategies for Children used by Preschool Teachers". The Personal Information Form was designed by the researchers to obtain preschool teachers' demographics.

During the data analysis, first, the normality of the data was tested. Accordingly, the data set was tested using the Kolmogorov-Smirnov test. Notes that the Kolmogorov Smirnov test should be used if the number $\mathrm{n}$ is 50 and above. The Mann-Whitney $\mathrm{U}$ test was used to examine preschool teachers' levels of career adaptability and using happiness-increasing strategies with respect to demographics such as gender and 
marital status. The Kruskal-Wallis $H$ test was used to evaluate preschool teachers' levels of career adaptability and using happiness-increasing strategies with respect to variables such as educational background, work experience, the institution of employment, career choice, and liking the job. Spearman's rank-order correlation was used to examine the relationship between preschool teachers' levels of career adaptability and using happiness-increasing strategies.

\section{Results}

Preschool teachers' scores in the Career Adaptability Scale and the Scale of Happiness Strategies for Children used by Preschool Teachers Scale did not statistically significantly differ according to gender, marital status, educational background, work experience, and the institution of employment.

Below are given preschool teachers' levels of career adaptability and using happiness-increasing strategies according to the variable of career choice. Accordingly, preschool teachers' levels of career adaptability and using happiness-increasing strategies differed significantly according to the variable of career choice. The preschool teachers who themselves chose their job (Group 1) had a significantly higher level of career adaptability and a mean rank compared to those who explained their career choice as "other" (Group 3). The preschool teachers who themselves chose their job (Group 1) had a significantly higher level of using happiness-increasing strategies and a mean rank compared to those who explained their career choice as "other" (Group 3).

There was a significant positive relationship between preschool teachers' career adaptability and happinessincreasing strategies that they used. It can be said that preschool teachers' levels of using happinessincreasing strategies increases as their career adaptability increases.

\section{Conclusion and Discussion}

Preschool teachers' levels of career adaptability and using happiness-increasing strategies differed significantly according to the variable of career choice. The preschool teachers who stated that "I myself chose my job" had significantly higher levels of career adaptability and using happiness-increasing strategies compared to those who said that "my family recommend my job" and those who explained their career choice as "other". It can thus be said that choosing the job willingly is an important factor for preschool teachers' career adaptability and their use of happiness-increasing strategies. Preschool teachers' levels of career adaptability and using happiness-increasing strategies differed significantly according to the variable of liking the job. Accordingly, preschool teachers who rated their liking of the job as "high" had significantly higher levels of career adaptability and using happiness-increasing strategies compared to those who rated their liking of the job as "medium" and "low". It can thus be said that the variable of liking the job is a factor that positively affects career adaptability and the use of happiness-increasing strategies.

Proposed effective strategies for improving happiness such as optimistic thinking, having an active life, extroversion, and reducing negative feelings. Reported that mothers use a variety of strategies to improve their children's happiness and these strategies positively affect children. 
The analysis results showed a significant positive relationship between preschool teachers' career adaptability and the happiness-increasing strategies that they used. Based on this result, it can be said that preschool teacher' levels of using happiness-increasing strategies increases as their career adaptability increases. Noted that individuals who choose the teaching profession should have high career aspirations, which will positively affect their career adaptability and by extension their teaching performance. 


\section{GİRİŞ}

İnsan yaşamının önemli bir sürecini içeren erken çocukluk dönemi, çocukların doğumundan itibaren başlayan ve sekiz yaşına kadar olan süreyi içine alan bir dönemdir (Tunçeli ve Zembat, 2017). İnsan yaşamının çok önemli bir bölümünü karşılayan bu dönemin çocukların bütüncül gelişimi anlamında verimli değerlendirmesi büyük bir önem arz etmektedir. Gelişimin en hızlı olduğu bu dönemde verilen eğitimin niteliği çok büyük bir önem taşımaktadır.

Erken çocukluk eğitimi veren eğitim kurumları, çocuğun yaşamına giren ilk örgün eğitim kurumudur. Çocuğun erken çocukluk eğitimi kurumlarındaki olumlu deneyim ve yaşantıları onun diğer eğitim kademelerinde aldığı eğitime karşı da olumlu bir motivasyona sahip olmasını sağlayacaktır. Erken çocukluk eğitimi kurumlarının en önemli unsuru öğretmendir.

Erken çocukluk eğitimi sürecinde, öğretmen oldukça önemlidir. Ancak iyi yetişmiş öğretmenler sayesinde belirlenmiş olan hedeflere ve amaçlara ulaşılabilir (Sak, 2005). Öğretmenler, planlı ve programlı çalışmalı, öğrencilerin bireysel farklılıklarını dikkate almalı, sınıfta düzen sağlayabilmeli, öğrencilerine dostça, sıcak ve sempatik davranmalı ve öğrencilerine eşit ve tarafsız olacak biçimde davranışlarda bulunmalıdır. Tüm bunlarla birlikte insan ilişkilerinde başarılı ve iyi bir vatandaş olmaları gerekmektedir (Ündar, 2005). Öğretmenlerin, meslekteki doyumu, mesleğine karşı tutumu, mesleğine bakış açısı ve meslekteki tükenme düzeyi gibi durumlar mesleki süreçlerini doğrudan etkileyen olgular arasında yer almaktadır (Demircan, 2008-akt. Toplu, 2012). Öğretmenlerin iş doyumları ve başarıları üzerinde etkili olan bir diğer husus ise kariyer uyumluluklarıdır.

İkinci Dünya savaşından sonraki dönemlerde yaşanan olaylar nedeniyle kariyer kavramı insanlar açısından önemli bir durum haline gelmiştir (Koca, 2009). Niles ve Harris-Bowlbey (2013)'e göre kariyer uyumluluğu, birey-çevre etkileşimini ve kariyer gelişiminde oluşabilecek değişikliklerle başa çıkma durumlarını kapsamaktadır. Zikic ve Klehe (2006), kariyer uyumluluğu üniversite (lisans) eğitimi ile başlayıp kariyerin sonlandırılması sürecine kadar devam eden, bireyin kişilik özellikleri, yetenekleri ve ilgileri doğrultusunda mesleğinin kendisine uygunluğu açısından değerlendirilerek, mesleğine göre kariyer hedeflerinin belirlenip kendilerine uygun olan kariyer amaçları doğrultusunda çalışması şeklinde tanımlamaktadır.

Bireylerin kariyer gelişiminin desteklenmesi sadece kendi hayatını olumlu yönde etkilememekte aynı zamanda içerisinde bulunduğu toplumun, yaşadığı ülkenin de kalkınmasına ve gelişmesine olumlu yönde katkı sağlamaktadır (Yeşilyaprak, 2013). Öğretmenler için kariyerlerini geliştirme arzusu, işlerine arzu ile yaklaşmalarını, yaptıkları işler aracıllı̆ıyla diğerlerine ve topluma katkıda bulunmalarını sağlamaktadır (Steger, Pickering, Shin ve Dik, 2010). Bu açıdan bakıldığında 
öğretmenlerin kariyer uyumluluklarının yüksek olmasının çocukların akademik başarıları ve sosyal duygusal gelişimlerini etkilediği söylenebilir.

Çocukların, okuldaki deneyimleri ve ilişkileri, tutum ve davranışları, çocukların akademik başarıları konusunda en önemli etken kuşkusuz öğretmenlerdir (Spilt, Koomen ve Thijs, 2011). Öğretmen eğitim sürecinin en önemli unsurudur ve çocukların kişilik gelişimleri ve diğer pek çok özellikleri üzerinde etkili olmaktadır (Topçu, 2016). Okul öncesi öğretmenleri, eğitim sürecindeki ve okul öncesi eğitimin niteliği üzerindeki en önemli faktördür (Barnett, 2003). Literatürde bulunan çalışmalar incelendiğinde çocukların akademik başarılarında ve mutluluk düzeylerinde öğretmenlerin yaklaşık olarak \%25’lik bir etki yarattıkları görülmektedir (Eryılmaz, 2014). Öğrenme sürecine en önemli katkı sağlayan faktörler arasında yer alan öğretmenlerin sınıf içerisinde öğrencileri ile kurdukları ilişki önemli bir yere sahiptir (Brekelmans, Wubbels ve Den Brok, 2002).

Öznel iyi oluş (mutluluk) yaşam sürecinden alınan doyum veya bireyin içerisinde bulundurduğu pozitif (olumlu) duyguların negatif (olumsuz) duygulardan daha fazla olması olarak tanımlanmaktadır (Diener, 1984). Çocuklar iki yaşından itibaren mutluluk, üzgünlük, kızgınlık ve korku gibi duyguları fark etmeye ve anlamaya başlamaktadırlar (Honig ve Brophy, 1996). Çocukların mutluluklarının attırılması, çevreleriyle olan etkileşimlerinde olumlu olmasına ve hayata olumlu bakış açısıyla bakmalarını sağlamaktadır. Bireyin yaşamının ilk yıllarında ümit duygusunun gelişmesi ve hayatın olumlu yönlerini görebilmesi için mutluluk duygusunun güçlü ve yüksek düzeyde olması gerekmektedir (Demiriz ve Ulutaş, 2016). Mutluluk ve yaşam doyumlarının azalması ise akademik başarının düşmesine, depresyon, sosyal sorunların ortaya çıkmasına, yalnızlık ve zararlı alışkanlıklara (madde bağımlılığı) yol açabilmektedir (Yucel ve Vogt Yuan, 2015). Gelişim ve öğrenmenin çok hızlı olduğu 2-6 yaş ilk çocukluk döneminde çocukların mutluluğundan sorumlu olan kişiler arasında öğretmenler de yer almaktadır (Eryılmaz, 2016). Okul öncesi öğretmenlerinin eğitim sürecinde kullandığı strateji, yöntem, teknik ve yaklaşımlar, çocuğun akademik başarısını, sosyal duygusal gelişimini, mutluluk düzeyini ve okul algısını olumlu veya olumsuz etkileme potansiyeline sahiptir.

Araştırma konusu ile ilgili literatür incelendiğinde, 1-5 yaş çocuğu bulunan annelerin kullandıkları mutluluk artırma stratejileri ölçeğinin geliştirilmesi (Eryılmaz ve Sapsağlam, 2018), okul öncesi öğretmenleri tarafindan kullanılan mutluluğu artırma stratejileri ölçeğinin geliştirilmesi (Bakkaloğlu, Eryılmaz ve Sapsağlam, 2019), farklı yaklaşımları sergileyen okul öncesi öğretmenlerinin çocuklarda düşünme becerilerini geliştirmek amacıyla kullandıkları stratejilerin incelenmesi (BüyüktaşkapuSoydan ve Dereli, 2016), okul öncesi dönemde çocuklarının mutluluk algısı (Türkiye ve Afganistan örneği) (Ünüvar, Çalışandemir, Tagay ve Amini, 2015), çocukların duyguları 
anlamaları ve duygularını kendi resimlerine yansıtmaları (Misailidi ve Bonoti, 2008), okul öncesi öğretmenlerin sınıf ortamlarında karşılaştıkları davranış problemleri ve kullandıkları yöntemler (Yağan-Güder, Alabay, Güner, 2018) gibi çalışmaların yapıldığı görülmektedir.

Yapılan araştırmalar sonucunda, okul öncesi öğretmenlerinin kariyer uyumlulukları ve kullandıkları mutluluk artırıcı stratejileri birlikte elen alan bir çalışmaya rastlanmamıştır. Okul öncesi öğretmenlerinin kariyer uyumlulukları ve çocuklar için kullandıkları mutluluk artırıcı stratejiler arasındaki ilişkinin incelenmesi amacıyla yapılan bu araştırmanın, literatürde henüz çalışılmamış ve özgün bir konuya dair önemli bulguları içermesi açsından önemli olduğu düşünülmektedir.

\section{YÖNTEM}

Araştırma, nicel araştırma yöntemlerinden alan ilişkisel tarama modelinde yürütülmüştür. Nicel araştırma yöntemine özgü bir araştırma deseni olan ilişkisel tarama deseni, iki veya daha fazla değişken arasında ilişki olup olmadığını ya da mevcut ilişkilerinin derecesini belirlemeyi amaçlayan bir araştırma modeli türüdür (Karasar,1999).

\section{Evren ve Örneklem}

Araştırmanın evrenini okul öncesi öğretmenleri, örneklemini ise Kırşehir ilinde bulunan okul öncesi eğitim kurumlarında 2019-2020 eğitim-öğretim y1lı güz döneminde görev yapan 229 okul öncesi öğretmeni oluşturmaktadır. Örneklem grubu, amaçlı örnekleme yöntemlerinden maksimum çeşitlilik örnekleme tekniğiyle belirlenmiştir. Maksimum çeşitlilik örnekleme, örneklemin problemle ilgili olarak kendi içinde benzeşik farklı durumlardan oluşturulmasıdır (Büyüköztürk, Akgün, Çakmak, Demirel ve Karadeniz 2017). Bu bağlamda farklı statülere sahip okul öncesi eğitim kurumlarında (resmi anaokulu, özel anaokulu ve anasınıfi) görev yapan okul öncesi öğretmenleri örneklem grubunda yer almıştır. Araştırmaya katılan okul öncesi öğretmenlerine ait demografik bilgiler aşağıda Tablo 1'de yer almaktadır.

Tablo 1. Örneklem Grubuna Ait Demografik Özellikler

\begin{tabular}{|c|c|c|c|}
\hline & & Frekans & Yüzde \\
\hline \multirow[b]{2}{*}{ Cinsiyet } & Erkek & 23 & 10 \\
\hline & Kadin & 206 & 90 \\
\hline \multirow[b]{2}{*}{ Medeni Durum } & Evli & 150 & 65,5 \\
\hline & Bekar & 79 & 34,5 \\
\hline \multirow{3}{*}{ Öğrenim Durumu } & Önlisans & 20 & 8,7 \\
\hline & Lisans & 196 & 85,6 \\
\hline & Lisansüstü & 13 & 5,7 \\
\hline \multirow[t]{2}{*}{ İş Deneyimi } & 1-9 Yil & 100 & 43,7 \\
\hline & 2021 & $\begin{array}{l}\text { dhood Studies } \\
\text { April }\end{array}$ & \\
\hline
\end{tabular}




\begin{tabular}{cccc} 
& $10-19$ Yıl & 93 & 40,6 \\
\hline \hline \multirow{2}{*}{ Çalıştığı Kurum Türü } & & 36 & 15,7 \\
& $20-29$ Yıl & 63 & 27,5 \\
& Anasınıfi & 79 & 34,5 \\
& Resmi Anaokulu & 87 & 38,0 \\
\hline \multirow{2}{*}{ Mesleğini Seçme Durumu } & Özel Anaokulu & 111 & 48,5 \\
& Kendim seçtim & 43 & 18,8 \\
& Ailem önerdi & 75 & 32,7 \\
\hline \multirow{2}{*}{ Mesleğini Sevme Düzeyi } & Diğger & 24 & 10,5 \\
& Düsük & 107 & 46,7 \\
& Orta & 98 & 42,8 \\
\hline
\end{tabular}

Araştırmanın örneklem grubunda yer alan katılıcıların demografik özelliklerine ilişkin Tablo 1'de yer alan bulgular incelendiğinde, cinsiyet değişkenine bağlı olarak kadınların ( $\mathrm{n}=206$ / \% 90), medeni durum değişkenine bağlı olarak evli olanların ( $\mathrm{n}=150$ / \% 65,5), öğrenin durumu değişkenine bağlı olarak lisans düzeyinde öğrenime sahip olanların ( $\mathrm{n}=196$ / \% 85,6), iş deneyimi değişkenine bağlı olarak 1-9 yıl arası iş deneyimi olanların ( $\mathrm{n}=100$ / \% 43,7), görev yapılan kurum türü değişkenine bağlı olarak özel anaokulunda çalışanların ( $\mathrm{n}=87$ / \% 38,0), mesleğini seçme durumu değişkenine bağlı olarak kendi seçenlerin ( $\mathrm{n}=111$ / \% 48,5) ve mesleğini sevme düzeyi değişkenine bağlı olarak orta düzeyde mesleğini sevenlerin ( $\mathrm{n}=107$ / \% 46,7) çoğunlukta olduğu görülmektedir.

\section{Veri Toplama Araçları}

Araştırma verilerinin toplanmasında katılımcıların kişisel bilgileriyle ilgili maddeler içeren "Kişisel Bilgi Formu”, "Kariyer Uyumluluğu Ölçeği” ve “Okul Öncesi Öğretmenlerinin Çocuklar İçin Kullandıkları Mutluluk Artırıcı Stratejiler Ölçeği” kullanılmıştır. Kişisel Bilgi Formu okul öncesi öğretmenlerinin demografik bilgilerini elde etmek amacıyla araştırmacılar tarafindan oluşturulmuştur. Eryılmaz ve Kara (2016) tarafindan geliştirilen Kariyer Uyumluluğu Ölçeği 10 maddeden oluşmakta ve iki alt boyuta ayrılmaktadır. Ölçeğin geçerlilik ve güvenirlik çalışmaları için Croncbach alfa ve test tekrar test yöntemi kullanılmıştır. Cronbach alfa sonuçlarında kariyer keşfi 0.84; kariyer planı 0.71 ve ölçeğini tamamı için 0.85 bulunmuştur. Geçerlilik çalışması ise yapı geçerliliğiyle yapılmıştır. Yapı geçerliliği için doğrulayıcı faktör analiz ve açımlayıcı faktör analizi tekniğinden yararlanılmıştır. Açımlayıcı faktör analizi sonuçları incelendiğinde; bu ölçme aracının iki boyutlu bir yap1 gösterdiği ve açıklanan varyansın \%55.87 olduğu görülmüştür. Doğrulayıc1 faktör analizi sonuçlarına bakıldığında ise iki boyutlu bu ölçme aracının RMSEA değerinin 0.071; serbestlik derecesinin 34 ve kay kare değerinin 70.75 olduğu tespit edilmiştir. Geliştirilen bu ölçme aracı için uyum iyiliği değerleri; NFI, 0.95; NNFI, 0.97; IFI, 0.98; CFI, 0.98; GFI, 0.94 ve AGFI, 
0.90'dur. Kabul edilebilir uyum iyiliği değerleri ise, RMSEA $0.05<$ RMSEA $<0.10$; NFI $0.90<\mathrm{NFI}<0.95$; CFI $0.90<\mathrm{NFI}<0.95$; GFI $0.90<\mathrm{NFI}<0.95($ Eryllmaz \& Kara, 2016).

Okul Öncesi Öğretmenlerinin Çocuklar İçin Kullandıkları Mutluluk Artırıcı Stratejiler Ölçeği, Bakkaloğlu, Eryılmaz ve Sapsağlam (2019) tarafindan geliştirilmiştir. Ölçek, Çocuklarla Pozitif İlişki Kurmak (1, 2, 3, 4), Çocukların İsteklerini Doyurmak (5,6,7) ve Çocuklarla Oyun Oynamak $(8,9,10,11,12)$ şeklinde üç boyut ve 12 maddeden oluşmaktadır. Ölçek güvenirliğinin ve ölçek maddelerinin iç tutarlılığının sınanması için Croncbach alfa katsayısı incelenmiştir. Cronbach alfa sonuçları, Çocuklarla Pozitif İlişki Kurmak (0.92), Çocukların İsteklerini Doyurmak (0.91) ve Çocuklarla Oyun Oynamak (0.80), ölçeğin tamamı için ise 0.93 olarak bulunmuştur. Ölçek geliştirme çalışmalarında Cronbach alfa sonuçlarının 0.70 ve üzeri olması gerekmektedir.

\section{Verilerin Toplanmas1}

Araştırma verileri araştırmacılar tarafından, Kırşehir ilinde bulunan okul öncesi eğitim kurumlarında görev yapan okul öncesi öğretmenlerinden toplanmıştır. Verilerin toplanması sürecinde öncelikle gerekli olan izinler İl Milli Ë̆itim Müdürlüğü’nden alınmıştır. Araştırmacılar tarafından okul öncesi öğretmenleriyle görev yaptıkları kurumlarda yüz yüze görüşülerek araştırmanın içeriği ve ölçme araçları hakkında bilgi verilmiş ve akabinde gönüllülük esasına bağlı olarak araştırmaya katılmak isteyen öğretmenler tarafindan ölçekler doldurulmuştur. Bu bağlamda 250 okul öncesi öğretmeninden veri toplanmıss, hatalı ve eksik işaretlemeler nedeniyle 21 katılımc1 tarafından doldurulan ölçekler değerlendirme dışı tutulmuş ve 229 katılımcıya ait ölçekler veri setinde yer almıştır. Araştırma verileri öğretmenlerin mesleki eğitimleri sırasında bireysel yoluyla toplanmıştır. Araştırmacılar tarafindan ölçme araçları ve puanlama hakkında okul öncesi öğretmenlerine bilgilendirme yapılmış ve sonrasında ölçme araçları uygulanarak formlar tekrar toplanmıştır. Veri toplama süreci yaklaşık 15 gün sürmüştür.

\section{Verilerin Analizi}

Araştırma verilerinin analizi sürecinde öncelikle verilerin normal dağılım gösterip göstermediği incelenmiştir. Bu amaçla veri seti Kolmogorow Smirnow testi ile sınanmıştır. Bu testin seçilmesinin nedeni katılımcı sayısının n=229 olmasıdır. Büyüköztürk (2011), n sayısının 50 ve üzeri olması durumunda Kolmogorow Smirnow testinin kullanılması gerektiğini belirtmektedir. Tablo 1'de görüldüğü üzere veri seti normal dağılım özelliği göstermemektedir $(p=, 000<.05)$. Bu sonuçlar doğrultusunda araştırma verilerinin analizinde parametrik olmayan testlerin kullanılmasına karar verilmiştir. 
Tablo 2. Normallik Testi Sonuçları

\begin{tabular}{lccc}
\hline & \multicolumn{2}{c}{ Kolmogorov-Smirnov(a) } \\
\cline { 2 - 4 } & Statistic & Df & Sig. \\
\hline Kariyer Uyumluluğu &, 197 & 229 &, 000 \\
\hline Mutluluk Artırıc1 Strateji Kullanımı &, 205 & 229 &, 000 \\
\hline
\end{tabular}

Tablo 2'de yer alan normallik testi sonuçlarına göre dağılımın normal olmadığı görülmüştür. Kolmogorow-Smirnov testinin ardından Skewness ve Kurtosis değerleri incelenmiş ve bu değerlerin; Huck (2008) tarafindan belirtilen normal dağılım referans değerlerine (-1 / +2) uygun olmadığı görülmüştür. Tüm bu bulgulardan yola çıkarak, analizlerde parametrik olmayan testlerin kullanılması kararlaştırılmıştır.

Okul öncesi öğretmenlerinin Kariyer Uyumluluğu ve Mutluluk Artırıcı Strateji Kullanımı düzeylerinin cinsiyet ve medeni durum gibi demografik özelliklerine göre incelenmesi amaciyla Mann Witney-U testi kullanılmaktadır. Okul öncesi öğretmenlerinin Kariyer Uyumluluğu ve Mutluluk Artırıcı Strateji Kullanımı düzeylerinin öğrenim durumu, iş deneyimi, çalıştığ kurum, mesleğini seçme ve mesleğini sevme gibi değişkenlere göre incelenmesi amacıyla Kruskal Wallis Varyans Analizi kullanılmaktadır. Okul öncesi öğretmenlerinin Kariyer Uyumluluğu ve Mutluluk Artırıcı Strateji Kullanımı düzeyleri arasında ilişki olup olmadığını incelemek amacıyla Spearman Korelasyon Analizi kullanılmıştır.

\section{BULGULAR}

Okul öncesi öğretmenlerinin Kariyer Uyumluluğu ve Mutluluk Artırıcı Strateji kullanma düzeylerine ilişkin puanlar, demografik özelliklerin bunlar üzerindeki etkisi ve ölçüm özellikleri arasındaki ilişkiye dair bulgular verilmiştir.

Tablo 3. Okul Öncesi Öğretmenlerinin Kariyer Uyumluluğu ve Mutluluk Artırıcı Strateji Puanlarının Cinsiyet Değişkenine Göre İncelenmesi

\begin{tabular}{|c|c|c|c|c|c|c|c|}
\hline Değişkenler & & & $\mathbf{N}$ & $\begin{array}{l}\text { Sira } \\
\text { Ort. }\end{array}$ & $\begin{array}{l}\text { Sira } \\
\text { Top. }\end{array}$ & $\mathbf{U}$ & $p$ \\
\hline Kariyer Uyumluluğu & Cinsiyet & $\begin{array}{l}\text { Erkek } \\
\text { Kadın }\end{array}$ & $\begin{array}{c}23 \\
206 \\
\end{array}$ & $\begin{array}{l}110,37 \\
115,52 \\
\end{array}$ & $\begin{array}{c}2538,50 \\
23796,50\end{array}$ & 2262,500 & ,719 \\
\hline $\begin{array}{l}\text { Mutluluk Artırıcı } \\
\text { Stratejiler }\end{array}$ & Cinsiyet & $\begin{array}{l}\text { Erkek } \\
\text { Kadın } \\
\text { Bekar }\end{array}$ & $\begin{array}{c}23 \\
206 \\
79\end{array}$ & $\begin{array}{l}107,57 \\
115,83 \\
107,13\end{array}$ & $\begin{array}{c}2474,00 \\
23861,00 \\
8463,27\end{array}$ & 2198,000 &, 557 \\
\hline
\end{tabular}


Tablo 3'de yer alan bulgular incelendiğinde, okul öncesi öğretmenlerinin Kariyer Uyumluluğu puanlar1 (U=2262,500; p>.05) ve Mutluluk Artırıc1 Strateji puanlarını (U=2198,000; p > .05), cinsiyet değişkenine göre istatiksel açıdan anlamlı düzeyde farklılaşmadığı görülmektedir.

Tablo 4. Okul Öncesi Öğretmenlerinin Kariyer Uyumluluğu ve Mutluluk Artırıcı Strateji Puanlarının Medeni Durum Değişkenine Göre İncelenmesi

\begin{tabular}{|c|c|c|c|c|c|c|c|}
\hline Değişkenler & & & $\mathbf{N}$ & $\begin{array}{l}\text { Sira } \\
\text { Ort. }\end{array}$ & $\begin{array}{l}\text { Sira } \\
\text { Top. }\end{array}$ & $\mathbf{U}$ & $p$ \\
\hline Kariyer Uyumluluğu & Medeni Durum & $\begin{array}{l}\text { Evli } \\
\text { Bekar } \\
\end{array}$ & $\begin{array}{l}150 \\
79 \\
\end{array}$ & $\begin{array}{l}120,25 \\
106,59 \\
\end{array}$ & $\begin{array}{c}18037,50 \\
8420,61 \\
\end{array}$ & 4887,500 & ,139 \\
\hline $\begin{array}{l}\text { Mutluluk Artırıcı } \\
\text { Stratejiler }\end{array}$ & Medeni Durum & $\begin{array}{l}\text { Evli } \\
\text { Bekar }\end{array}$ & $\begin{array}{c}150 \\
79\end{array}$ & $\begin{array}{l}119,74 \\
107,13\end{array}$ & $\begin{array}{l}17961,00 \\
8463,27\end{array}$ & 4941,000 & ,168 \\
\hline
\end{tabular}

Tablo 4'te yer alan bulgular incelendiğinde, okul öncesi öğretmenlerinin Kariyer Uyumluluğu puanları (U=4887,500; p>.05) ve Mutluluk Artırıcı Strateji puanlarının (U=4941,000; p>.05), medeni durum değişkenine göre istatiksel açıdan anlamlı düzeyde farklılaşmadığı görülmektedir.

Tablo 5. Okul Öncesi Öğretmenlerinin Kariyer Uyumluluğu ve Mutluluk Artırıcı Strateji Puanlarının Öğrenim Durumu Değişkenine Göre İncelenmesi

\begin{tabular}{|c|c|c|c|c|c|c|c|}
\hline Değişkenler & & & $\mathbf{N}$ & $\begin{array}{l}\text { Sira } \\
\text { Ort. }\end{array}$ & sd & $\chi^{2}$ & $p$ \\
\hline \multirow[t]{3}{*}{ Kariyer Uyumluluğu } & Öğrenim & Önlisans & 20 & 146,28 & 2 & 6,403 & ,041 \\
\hline & Durumu & Lisans & 196 & 113,35 & & & \\
\hline & & Lisansüstü & 13 & 91,81 & & & \\
\hline \multirow[t]{3}{*}{ Mutluluk Artırıcı Stratejiler } & Öğrenim & Önlisans & 20 & 124,28 & 2 & ,923 & ,630 \\
\hline & Durumu & Lisans & 196 & 114,89 & & & \\
\hline & & Lisansüstü & 13 & 102,38 & & & \\
\hline
\end{tabular}

Tablo 5’te okul öncesi öğretmenlerinin Kariyer Uyumluluğu ve Mutluluk Artırıcı Strateji Kullanımı düzeylerinin öğrenim durumu değişkenine göre incelenmesine ilişkin bulgular yer almaktadır. Bu duruma göre, okul öncesi öğretmenlerinin Kariyer Uyumluluğu düzeyleri $(\chi 2=6,403$; sd=2; $<<.05)$ öğrenim durumuna göre anlamlı düzeyde farklılaşırken, Mutluluk Artırıcı Strateji Kullanımı düzeyleri $\left(\chi^{2}=, 923 ; \mathrm{sd}=2 ; \mathrm{p}>\right.$.05) öğrenim durumu değişkenine göre düzeyde farklılaşmamaktadır.

Tablo 6. Okul Öncesi Öğretmenlerinin Kariyer Uyumluluğu ve Mutluluk Artırıcı Strateji Puanlarının İş Deneyimi Değişkenine Göre İncelenmesi

\begin{tabular}{|c|c|c|c|c|c|c|c|}
\hline Değişkenler & & & $\mathbf{n}$ & $\begin{array}{l}\text { Sira } \\
\text { Ort. }\end{array}$ & sd & $\chi^{2}$ & $p$ \\
\hline \multirow[t]{3}{*}{ Kariyer Uyumluluğu } & İş Deneyimi & 1-9 Yil & 100 & 115,58 & 2 & ,669 & ,716 \\
\hline & & 10-19 Yil & 93 & 111,67 & & & \\
\hline & & 20-29 Y1l & 36 & 122,00 & & & \\
\hline \multirow[t]{3}{*}{ Mutluluk Artırıcı Stratejiler } & İş Deneyimi & 1-9 Yil & 100 & 111,96 & 2 & 1,110 & 574 \\
\hline & & 10-19 Yil & 93 & 114,40 & & & \\
\hline & & 20-29 Y1l & 36 & 125,00 & & & \\
\hline
\end{tabular}


Tablo 6’te okul öncesi öğretmenlerinin Kariyer Uyumluluğu ve Mutluluk Artırıcı Strateji Kullanımı düzeylerinin iş deneyimi değişkenine göre incelenmesine ilişkin bulgular yer almaktadır. Bu duruma göre, okul öncesi öğretmenlerinin Kariyer Uyumluluğu düzeyleri $\left(\chi^{2}=, 669 ; \mathrm{sd}=2 ; \mathrm{p}>.05\right)$ ve Mutluluk Artırıcı Strateji Kullanımı düzeyleri $\left(\chi^{2}=1,110 ; \mathrm{sd}=2 ; \mathrm{p}>.05\right)$ iş deneyimi değişkenine göre anlamlı düzeyde farklılaşmamaktadır.

Tablo 7. Okul Öncesi Öğretmenlerinin Kariyer Uyumluluğu ve Mutluluk Artırıcı Strateji Puanlarının Çalıştığ Kurum Değişkenine Göre İncelenmesi

\begin{tabular}{|c|c|c|c|c|c|c|c|}
\hline Değişkenler & & & $\mathbf{n}$ & $\begin{array}{l}\text { Sira } \\
\text { Ort. }\end{array}$ & sd & $\chi^{2}$ & $p$ \\
\hline \multirow[t]{3}{*}{ Kariyer Uyumluluğu } & Çalıştığ & Anasinifi & 63 & 100,29 & 2 & 7,822 & 020 \\
\hline & Kurum & Resmi Anaokulu & 79 & 110,84 & & & \\
\hline & & Özel Anaokulu & 87 & 129,43 & & & \\
\hline \multirow[t]{3}{*}{ Mutluluk Artırıc1 Stratejiler } & Çalıştığ & Anasınıfi & 63 & 101,07 & 2 & 6,340 & ,042 \\
\hline & Kurum & Resmi Anaokulu & 79 & 112,48 & & & \\
\hline & & Özel Anaokulu & 87 & 127,37 & & & \\
\hline
\end{tabular}

Tablo 7'de okul öncesi öğretmenlerinin Kariyer Uyumluluğu ve Mutluluk Artırıc1 Strateji Kullanımı düzeylerinin çalıştı̆̆ kurum değişkenine göre incelenmesine ilişkin bulgular yer almaktadır. Buna göre, okul öncesi öğretmenlerinin Kariyer Uyumluluğu düzeyleri $\left(\chi^{2}=7,822 ; \mathrm{sd}=2 ; \mathrm{p}<.05\right)$ ve Mutluluk Artırıcı Strateji Kullanımı düzeyleri $(\chi 2=6,340 ; \mathrm{sd}=2 ; \mathrm{p}<.05)$ çalıştığı kurum değişkenine göre anlamlı düzeyde farklılaşmaktadır. Sıra ortalamaları incelendiğinde özel anaokulunda çalışan öğretmenlerin kariyer uyumluluk düzeylerinin ve mutluluk artırıcı strateji kullanım düzeylerinin diğer gruplara göre daha yüksek olduğu görülmektedir.

Tablo 8. Okul Öncesi Öğretmenlerinin Kariyer Uyumluluğu ve Mutluluk Artırıcı Strateji Puanlarının Mesleğini Seçme Değişkenine Göre İncelenmesi

\begin{tabular}{|c|c|c|c|c|c|c|c|c|}
\hline Değişkenler & & & $\mathbf{n}$ & $\begin{array}{l}\text { Sira } \\
\text { Ort. }\end{array}$ & sd & $\chi^{2}$ & $p$ & $\begin{array}{c}\text { Gruplar } \\
\text { Arasi } \\
\text { Fark }\end{array}$ \\
\hline Kariyer Uyumluluğu & $\begin{array}{l}\text { Mesleğini } \\
\text { Seçme }\end{array}$ & $\begin{array}{l}\text { 1.Kendim seçtim } \\
\text { 2.Ailem önerdi } \\
\text { 3.Diğer }\end{array}$ & $\begin{array}{c}111 \\
43 \\
75\end{array}$ & $\begin{array}{r}136,24 \\
106,36 \\
88,51\end{array}$ & 2 & 25,033 & 000 & $1-3$ \\
\hline $\begin{array}{l}\text { Mutluluk Artırıcı } \\
\text { Stratejiler }\end{array}$ & $\begin{array}{l}\text { Mesleğini } \\
\text { Seçme }\end{array}$ & $\begin{array}{l}\text { 1.Kendim 2.seçtim } \\
\text { 3.Ailem önerdi } \\
\text { Diğer }\end{array}$ & $\begin{array}{c}111 \\
43 \\
75\end{array}$ & $\begin{array}{r}132,75 \\
100,69 \\
96,93\end{array}$ & 2 & 16,620 & ,000 & $\begin{array}{ll}1-3 \\
\end{array}$ \\
\hline
\end{tabular}

Tablo 8'de okul öncesi öğretmenlerinin Kariyer Uyumluluğu ve Mutluluk Artırıcı Strateji Kullanımı düzeylerinin mesleğini seçme değişkenine göre incelenmesine ilişkin bulgular yer almaktadır. Buna göre, okul öncesi öğretmenlerinin Kariyer Uyumluluğu düzeyleri $(\chi 2=25,033$; sd= 2; $p<.05)$ ve Mutluluk Artırıcı Strateji Kullanımı düzeyleri $(\chi 2=16,620 ; \mathrm{sd}=2 ; \mathrm{p}<.05)$ mesleğini seçme 
değişkenine göre anlamlı düzeyde farklılaşmaktadır. Anlamlı farkın hangi gruplar arasında olduğunu belirlemek amacıyla ikili karşılaştırmalarda tercih edilen Mann Whitney-U testi yapılmıştır.

Buna göre okul öncesi öğretmenlerinden mesleğimi "kendim seçtim” diyenlerin (Grup 1) Kariyer Uyumluluk düzeyleri ve sıra ortalamaları meslek seçimini “diğer” (Grup 3) şeklinde belirtenlerden anlamlı derecede daha yüksektir $(U=2418,500 ; z-4,910 ; p=, 000)$. Okul öncesi öğretmenlerinden mesleğimi "kendim seçtim” diyenlerin (Grup 1) Mutluluk Artırıcı Strateji Kullanma düzeyleri ve sıra ortalamaları meslek seçimini “diğer” (Grup 3) şeklinde belirtenlerden anlamlı derecede daha yüksektir (U=2870,500; z-3,696; p=,000).

Tablo 9. Okul Öncesi Öğretmenlerinin Kariyer Uyumluluğu ve Mutluluk Artırıcı Strateji Puanlarının Mesleğini Sevme Değişkenine Göre İncelenmesi

\begin{tabular}{|c|c|c|c|c|c|c|c|c|}
\hline Değişkenler & & & n & $\begin{array}{l}\text { S1ra } \\
\text { Ort. }\end{array}$ & sd & $\chi^{2}$ & $p$ & $\begin{array}{c}\text { Gruplat } \\
\text { Aras1 } \\
\text { Fatk }\end{array}$ \\
\hline Kariyer Uyumluluğu & $\begin{array}{l}\text { Mesleğini } \\
\text { Sevme }\end{array}$ & $\begin{array}{l}\text { 1.Düşük } \\
\text { 2.Orta } \\
\text { 3.Yüksek }\end{array}$ & $\begin{array}{c}24 \\
107 \\
98\end{array}$ & $\begin{array}{r}28,60 \\
95,01 \\
157,98\end{array}$ & 2 & 95,228 & , 000 & $\begin{array}{l}1-2 \\
1-3 \\
2-3\end{array}$ \\
\hline $\begin{array}{l}\text { Mutluluk Artırıci } \\
\text { Stratejiler }\end{array}$ & $\begin{array}{l}\text { Mesleğini } \\
\text { Sevme }\end{array}$ & $\begin{array}{l}\text { 1.Düşük } \\
\text { 2.Orta } \\
\text { 3.Yüksek }\end{array}$ & $\begin{array}{c}24 \\
107 \\
98\end{array}$ & $\begin{array}{r}34,04 \\
101,36 \\
149,71\end{array}$ & 2 & 71,887 & ,000 & $\begin{array}{l}1-2 \\
1-3 \\
2-3\end{array}$ \\
\hline
\end{tabular}

Tablo 9'da okul öncesi öğretmenlerinin Kariyer Uyumluluğu ve Mutluluk Artırıcı Strateji Kullanımı düzeylerinin mesleğini sevme değişkenine göre incelenmesine ilişkin bulgular yer almaktadır. Buna göre, okul öncesi öğretmenlerinin Kariyer Uyumluluğu düzeyleri $(\chi 2=95,228$; sd= 2; $\mathrm{p}<.05)$ ve Mutluluk Artırıcı Strateji Kullanımı düzeyleri $(\chi 2=71,887 ; \mathrm{sd}=2 ; \mathrm{p}<0.5)$ mesleğini sevme değişkenine göre anlamlı düzeyde farklılaşmaktadır. Anlamlı farkın hangi gruplar arasında olduğunu belirlemek amacıyla ikili karşılaştırmalarda tercih edilen Mann Whitney-U testi yapılmıştır.

Buna göre okul öncesi öğretmenlerinden mesleğini sevme düzeyini "düşük" olarak belirtenlerin (Grup 1) Kariyer Uyumluluk düzeyleri ve sıra ortalamaları mesleğini sevme düzeyini “orta” (Grup 2) olarak belirtenlerden $(U=315,500 ; z=-5,998 ; p=, 000)$, mesleğini sevme düzeyini “düşük” olarak belirtenlerin (Grup 1) Kariyer Uyumluluk düzeyleri ve sıra ortalamaları mesleğini sevme düzeyini “yüksek" (Grup 3) olarak belirtenlerden ( $U=71,000 ; z=-7,220 ; p=, 000)$, mesleğini sevme düzeyini “orta” olarak belirtenlerin (Grup 2) Kariyer Uyumluluk düzeyleri ve sira ortalamaları mesleğini sevme düzeyini “yüksek" (Grup 3) olarak belirtenlerden (U=2136,000; z=-7,488; p=,000) anlamlı derecede daha düşüktür.

Okul öncesi öğretmenlerinden mesleğini sevme düzeyini "düşük” olarak belirtenlerin (Grup 1) Mutluluk Artırıcı Strateji kullanım düzeyleri ve sıra ortalamaları mesleğini sevme düzeyini "orta" 
(Grup 2) olarak belirtenlerden ( $U=377,500 ; z=-5,918 ; p=, 000)$, mesleğini sevme düzeyini "düşük" olarak belirtenlerin (Grup 1) Mutluluk Artırıcı Strateji kullanım düzeyleri ve sıra ortalamaları mesleğini sevme düzeyini “yüksek” (Grup 3) olarak belirtenlerden ( $U=139,500 ; z=-6,802 ; p=, 000)$, mesleğini sevme düzeyini “orta” olarak belirtenlerin (Grup 2) Mutluluk Artırıcı Strateji kullanım düzeyleri ve sıra ortalamaları mesleğini sevme düzeyini "yüksek” (Grup 3) olarak belirtenlerden $(\mathrm{U}=2877,500 ; \mathrm{z}=-5,783 ; \mathrm{p}=, 000)$ şeklinde belirtenlerden anlamlı derecede daha düşüktür.

Tablo 10. Kariyer Uyumluluğu ve Mutluluk Artırıcı Strateji Puanları Arasındaki İlişkiyi Gösteren Spearman Korelasyon Analizi Sonuçları

\begin{tabular}{lcc}
\hline & Kariyer Uyumluluğu & Mutluluk Artırıc1 Strateji Kullanımı \\
\cline { 2 - 3 } Kariyer Uyumluluğu & 1 & 1 \\
Mutluluk Artırıcı Strateji Kul. & $.669(* *)$ & .000 \\
\hline
\end{tabular}

$\mathrm{P}<.001$ düzeyinde anlamlı ilişki

Tablo 10'da yer alan, Okul Öncesi Öğretmenlerinin Kariyer Uyumlulukları ile Kullandıkları Mutluluk Artırıcı Stratejiler arasında anlamlı bir ilişki olup olmadığını belirlemek amacıyla yapılan Spearman korelasyon analizi sonucuna göre, okul öncesi öğretmenlerinin kariyer uyumlulukları ile kullandıkları mutluluk artırıcı stratejiler arasında pozitif yönde ve anlamlı bir ilişki olduğu görülmektedir ( $\mathrm{r}=.669, \mathrm{p}<.01)$. Okul öncesi öğretmenlerinin kariyer uyumlulukları arttıkça mutluluk artırıcı stratejileri kullanma düzeylerinin de artacağı söylenebilir.

\section{SONUÇ ve TARTIŞMA}

Okul öncesi Öğretmenlerinin Kariyer Uyumlulukları ve Çocuklar İçin Kullandıkları Mutluluk Artırıcı Stratejiler arasındaki ilişkinin incelenmesi amacıyla yapılan araştırmada, nicel araştırma desenlerinden ilişkisel tarama modeli tercih edilmiş ve araştırmanın örneklemini farklı okul öncesi eğitim kurumlarında görevli olan 229 okul öncesi öğretmeni oluşturmuştur.

Elde edilen bulgular incelendiğinde, okul öncesi öğretmenlerinin Kariyer Uyumluluğu puanlarının ve Mutluluk Artırıcı Strateji puanlarının, cinsiyet, medeni durum ve iş deneyimi değişkenine göre istatiksel açıdan anlamlı düzeyde farklılaşmadığı görülmüştür. Bununla birlikte araştırmaya katılan okul öncesi öğretmenlerinin Kariyer Uyumluluğu düzeyleri öğrenim durumuna göre anlamlı düzeyde farklılaşırken, Mutluluk Artırıcı Strateji Kullanımı düzeyleri öğrenim durumu değişkenine göre farklılaşmamaktadır. Okul öncesi öğretmenlerinin Kariyer Uyumluluğu ve Mutluluk Artırıc1 Strateji Kullanımı düzeylerinin çalışığı kurum değişkenine göre anlamlı düzeyde farklılaşmaktadır. Sıra ortalamaları incelendiğinde özel anaokulunda çalışan öğretmenlerin kariyer uyumluluk düzeylerinin ve mutluluk artırıcı strateji kullanım düzeylerinin diğer gruplara göre daha yüksek olduğu görülmüştür. Erus ve Zeren (2017) tarafindan 260 öğretmen adayı ile yapılan araştırmada 
kariyer uyumunun öğrencilerin mezun olunan bölümüne, medeni durumuna ve cinsiyetine göre değissip değişmediği incelenmiştir. Araştırma sonucunda öğretmen adaylarının kariyer uyumlarında medeni duruma, mezun olunan bölüme ve cinsiyete göre anlamlı bir farklıllı̆ın bulunmadığ1 görülmüştür. Bir diğer araştırmada ön lisans düzeyinde öğrenim gören üniversite öğrencilerinin demografik özelliklerinin kariyer uyumluluğu ve iyimserliği ile ilişkisi incelenmiş ve kariyer uyumluluğunun cinsiyet değişkenine göre farklllaşmadığı görülmüştür (Gül, Maksüdünov, Yamaltdinova ve Abdildaev, 2019). Kariyer uyumu, kişinin çalışma hayatında yaşadığ1 travma durumlarında kendi kendini düzenleme gücüne ve sorunlarını başarılı bir şekilde çözmesine yardımcı olmaktadır (Bimrose ve Hearne, (2012); Klehe, Zikic, Van Vianen ve De Pater (2011).

Araştırmaya katılan okul öncesi öğretmenlerinin Kariyer Uyumluluğu ve Mutluluk Artırıcı Strateji Kullanımı düzeylerinin mesleğini seçme değişkenine göre anlamlı düzeyde farklılaştığı görülmüştür. Okul öncesi öğretmenlerinden mesleğimi "kendim seçtim” diyenlerin Kariyer Uyumluluğu ve Mutluluk Artırıcı Strateji Kullanımı düzeylerinin meslek seçimini “ailem önerdi” ve “diğer” şeklinde belirtenlerden anlamlı derecede daha yüksek olduğu ortaya çıkmıştır. Bu sonuç dikkate alındığında okul öncesi öğretmenleri için mesleğini isteyerek seçmenin kariyer uyumluluğu ve mutluluk stratejisi kullanımı üzerinde önemli bir etken olduğu söylenebilir. Okul öncesi öğretmenlerinin Kariyer Uyumluluğu ve Mutluluk Artırıcı Strateji Kullanımı düzeylerinin mesleğini sevme değişkenine göre anlamlı düzeyde farklılaştığı görülmüştür. Buna göre okul öncesi öğretmenlerinin mesleğini sevme düzeyini "yüksek” olarak belirtenlerin Kariyer Uyumluluk düzeyleri ve Mutluluk Artırıcı Strateji kullanım düzeyleri mesleğini sevme düzeyini "orta" ve "düşük" olarak belirtenlerden anlamlı derecede daha yüksektir. Bu sonuçtan yola çıkarak mesleğini sevme değişkeninin kariyer uyumu ve mutluluk artırıcı strateji kullanımı üzerinde olumlu bir etken olduğu söylenebilir. Literatürde öznel iyi oluşu artırma stratejileri üzerine ilk çalışmalar Fordyce (1983) tarafindan yapılmıştır. Fordyce (1983) mutluluğu artırmaya yönelik aktif bir yaşam sürme, iyimser düşünme, olumsuz düşüncelere yer vermeme ve sosyal olma gibi etkili stratejiler önermiştir. Eryılmaz ve Sapsağlam, (2018) tarafından yapılan araştırma, annelerin çocuklarının mutluluğunu artırmaya yönelik çeşitli stratejiler kullandıklarını ve bu stratejilerin çocukları olumlu etkilediğini göstermektedir. Büyüktaşkapu Soydan ve Dereli (2016) tarafından yapılan araştırma öncesi öğretmenlerinin çocukların düşünme becerilerini desteklemek için çeşitli çeşitli stratejiler kullandıklarını göstermektedir.

Okul öncesi öğretmenlerinin Kariyer Uyumluluğu ve Mutluluk Artırıcı Strateji Kullanımı düzeyleri arasında anlamlı bir ilişki olup olmadığına yönelik bulgular, okul öncesi öğretmenlerinin kariyer uyumlulukları ile kullandıkları mutluluk artırıcı stratejiler arasında pozitif yönde ve anlamlı bir ilişki olduğunu göstermektedir. Bu sonuçtan yola çıkarak okul öncesi öğretmenlerinin kariyer 
uyumluluklarının artmasıyla mutluluk artırıcı strateji kullanma düzeylerinin de artacağı söylenebilir. Eryllmaz ve Kara (2017) öğretmenlik mesleğini tercih edecek olan bireylerin yüksek kariyer arzusunu içlerinde bulundurmaları gerektiğini ve bunun kariyer uyumluluğunu dolayısıyla öğretmenlik performansını olumlu etkileyeceğini belirtmektedir. Araştırmalar kariyer uyumluluğunun artmasıyla birlikte öğretmenlerin ve öğretmen adaylarının kariyer iyimserliklerinin ve öz-yeterliliklerinin (McLennan, McIlveen ve Perera, 2017) ve iş doyumlarının (Wang, Hall ve Rahimi, 2015) da arttığını göstermektedir.

Bu çalışmalar dışında öğretmenlerin ve öğretmen adaylarının kariyer uyumluluklarının artırılmasına dayanak oluşturabilecek çalışmalara ihtiyaç vardır.

Araştırma sonuçları doğrultusunda,

- Meslek seçiminin bilinçli yapılmasının kariyer uyumluluğunu artıran bir faktör olması nedeniyle, bilinçli meslek seçimi konusunda çocukların ve ailelerinin desteklenmesi,

- Kariyer uyumluluğunun bireyin mesleki performansı üzerinde etkili bir husus olmas1 nedeniyle çalışanların kariyer uyumluluklarının desteklenmesi,

- Kariyer Uyumluluğu ve Mutluluk Artırıcı Strateji Kullanımı üzerinde etkili olabilecek diğer değişkenlerin de araştırılması önerilmektedir.

\section{KAYNAKÇA}

Bakkaloğlu, A. B., Eryllmaz, A., \& Sapsağlam, Ö. (2019). Thescale of happinessstrategiesforchildren'susedbypreschoolteachers. Journal ComputerandEducationResearch, 7 (13), 171-182. DOI: 10.18009/jcer.535593

Barnet, W. S. (2003). Beter teachers, beter preschols: Studentachievementlinkedtoteacherqualifications. NIER PrescholPolicyMaters, 2, 1-11.

Bimrose, J. \&Hearne, L. (2012) Resilienceandcareeradaptability: Qualitativestudies of adultcareercounseling. Journal of VocationalBehavior, 81, 338-344.

Brekelmans, M., Wubbels, T., \& Den Brok, P. (2002). Teacherexperienceandtheteacherstudentrelationship. In S. C. Goh\& M. S. Khine (Eds.), Studies in educationallearningenvironments: An internationalperspective (pp. 73-99). Singapore: World Scientific.

Büyüköztürk, Ş. (2011). Sosyal bilimler için veri analiz̨i el kitabl-istatistik, araștırma deseni, spss uygulamalar ve yorum (15. Baski). Ankara: Pegem Akademi 
Büyüköztürk, Ş., Akgün, Ö. E., Çakmak, E. K., Demirel, F., ve Karadeniz, Ş. (2017). Bilimsel araştırma yöntemleri. Ankara: Pegem Akademi.

Büyüktaşkapu Soydan, S. \& Dereli, H. (2016). Farklı yaklaşımları uygulayan okul öncesi öğretmenlerinin çocuklarda düşünme becerilerini geliştirmek için kullandıkları stratejilerin incelenmesi. Kastamonu Eğitim Dergisi, 22 (2), 475-496. Retrievedfromhttps://dergipark.org.tr/en/pub/kefdergi/issue/22602/241501

Demiriz, S. \& Ulutaş, İ. (2016). Çocuklar ne kadar mutlu? Bazı değişkenlere göre çocuklarda mutluluğun belirlenmesi. Adnan Menderes Üniversitesi Ĕgitim Fakültesi Eğitim Bilimleri Dergisi, 7 (1), s. 16-24.

Diener, E. (1984). Subjectivewell-being. PsychologicalBulletin 95, 542- 575.

Erus, S. M. \& Zeren, S, G. (2017) Öğretmen adaylarının öğretmenlik mesleğine yönelik kariyer uyumlar1. Yülesekögretim ve Bilim Dergisi, 7 (3), 657-668.

Eryllmaz, A. (2014). Perceivedpersonalitytraitsandtypes of teachersandtheirrelationshiptothesubjectivewell-beingandacademicachievements of adolescents. EducationalSciences: TheoryandPractice, 14 (6), 2049-2062.

Eryllmaz, A. (2016). Herkes için mutluluğun başucu kitabı: Teoriden uygulamaya pozititif psikoloji. Ankara: Pegem Akademi.

Eryllmaz, A., \& Kara, A. (2016). Investigation of psychometricproperties of careeradaptabilityscale. The Online Journal of CounselingandEducation, 5(1), 29-39.

Eryllmaz, A. \& Kara, A. (2017). A careeradaptability model forpre-service teachers. Erzincan Üniversitesi Eğitim Fakültesi Dergisi, 20 (2), 352-365.

Eryllmaz, A., \& Sapsağlam, Ö. (2018). Development of subjectivewellbeingincreasingstrategiesscaleforchildren (1-5 Ages) theirmothersuse. Journal of Educationand Training Studies, 6 (6), 77-83.

Fordyce, M. W. (1983). A program toincreasehappiness: furtherstudies. J CounsPsychol, 30, p.483498.

Guil, H., Maksüdünov, A., Yamaltdinova, A. \&Abdildaev, M. (2019). Öğrencilerin demografik özelliklerinin kariyer uyumluluğu ve iyimserliği ile ilişkisi: Kırgızistan örneği. KMU“Sosyal ve Ekonomik. Araştırmalar Dergisi 21 (36), 34-46.

Honig, A. S. \&Brophy, H. E. (1996). Talkingwithyourbaby: family as thefirstschool. Syracuse: SyracuseUniversity Pres.

Huck, S. W. (2008). Reading staticsandresearch (5rd edition). New York: AddisonWesleyLongman.

Karasar, N. (1999). Bilimsel araștırma yöntemi. Ankara: Nobel Yayın Dağıtım. 
Klehe, U. C., Zikic, J., Van Vianen, A. E. M. \& De Pater, I. E. (2011). Careeradaptability, turnoverandloyaltyduringorganizationaldownsizing. Journal of VocationalBehavior, 79, 217229.

Koca, A. İ. (2009). Üniversite ögrencilerinin değerleri ve bireysel özellikleri ile kariyer tercibleri arasindaki ilişki: Cukurova üniversitesinde bir araștırma. Yüksek Lisans Tezi, Çukurova Üniversitesi, Sosyal Bilimler Enstitüsü, Adana.

McLennan, B., McIlveen, P., \&Perera, H. N. (2017). Pre-service teachers' selfefficacymediatestherelationshipbetweencareeradaptabilityandcareeroptimism.

TeachingandTeacherEducation, 63, 176-185. doi:10.1016/j.tate.2016.12.022

Misailidi, P. \&Bonoti, F. (2008). Emotion in children's art do youngchildrenunderstandtheemotionsexpressed in otherchildren'sdrawings? Journal of EarlyChildhoodResearch, 6 (2), 189-200. doi: 10.1177/1476718X08088677

Niles, S, G,„\&Harrıs-Bowlsbey, J. (2013). 21. Yü̈ynlda kariyer gelişimi müdahaleleri (F, K, OWEN, C,ev,) Ankara: Nobel Yayınevi.

Sak, R. (2005). Erkek okul öncesi ögretmenlerinin göreve başladıklarnnda karşılaştıklar durumlar ve bu ögretmenlerin velilerinin erkek okul öncesi ögretmenleri hakkendaki düsünceleri. Yüksek Lisans Tezi, Gazi Üniversitesi Eğitim Bilimleri Enstitüsü, Ankara.

Spilt, J. L., Koomen, H. M., \&Thijs, J. T. (2011). Teacherwellbeing: Theimportance of teacherstudentrelationships. EducationalPsychologyReview, 23 (4), 457-477.

Steger, M. F., Pickering, N., Shin, J. Y., \& Dik, B. J. (2010). Calling in work: Secularorsacred? Journal of CareerAssessment, 18, 82-96.

Topçu, N. (2016). Türkiye’nin maarif davası. İstanbul: Dergâh Yayınları.

Toplu, Y. N. (2012). Okul öncesi ve ilkë̈gretim öğretmenlerinin tükenmişlik düzeyleri. Yüksek Lisans Tezi, Adnan Menderes Üniversitesi, Sosyal Bilimler Enstitüsü, Aydın.

Tunçeli, H. İ. \&Zembat, R. (2017). Erken çocukluk döneminde gelişimin değerlendirilmesi ve önemi. Eğitim Kuram ve Uygulama Arastormalar Dergisi, 3 (3), 1-12.

Ündar, E. (2005). Okul öncesi ögretmenlerinin kişilik özelliklerinin iş tatminleri üzerindeki etkisi. Yüksek Lisans Tezi, Marmara Üniversitesi, Eğitim Bilimleri Enstitüsü, İstanbul.

Ünüvar, P., Çalışandemir, F., Tagay, Ö. \&Amini, F. (2015). Okul öncesi dönem çocuklarının mutluluk alg1sı (Türkiye ve Afganistan Örneği). Mehmet Akif Ersoy Üniversitesi Ë̆itim Fakültesi Dergisi, 34, 1-22.

Yağan-Güder, S., Alabay, E. \& Güner, E. (2018). Okul öncesi öğretmenlerinin sinıflarında karşılaştıkları davranış problemleri ve kullandıkları stratejiler. İlköğretim Online, 17(1), 414430 .

Yeşilyaprak, B. (2013). Mesleki rehberlik ve kariyer damışmanlğg: Kuramdan uygulamaya. Ankara: Pegem Yayıncilik. 
Yucel, D. \& Vogt Yuan, A. S. (2016). Parents, siblings, or friends? Exploring life satisfaction among early adolescents. Applied Research Quality Life, 11, p. 399-423. doi.10.1007/ s11482-0159444-5.

Wang, H., Hall, N. C., \& Rahimi, S. (2015). Self-efficacy and causal attributions in teachers: Effects on burnout, job satisfaction, illness, and quitting intentions. Teaching and Teacher Education, 47, 120-130. http://dx.doi.org/10.1016/ j.tate.2014.12.005.

Zikic, J. \&Klehe, U. C. (2006). Job loss as a blessing in disguise: The role of career exploration and career planning in predicting reemployment quality. Journal of Vocational Behavior, 69, 391409. doi: $10.1016 /$ j.jvb.2006.05.007 